\title{
In Memoriam: Hilary Booth
}

This issue of The ANZIAM Journal is dedicated to the memory of Dr Hilary Booth, who died from heart failure on May $26^{\text {th }}$ at the early age of 48 after a lifetime battling cancer. After taking a B.Sc. at The University of Adelaide with a major in Mathematical Physics, she was a full-time artist for some years before returning to the academic world. She obtained her Ph.D. at The University of New England in 1999, with a thesis entitled The Static Maxwell-Dirac Equations. Hilary was a very visible figure on the Australian scene in mathematical physics, mathematics and finally bioinformatics, in which her mathematical creativity found its fullest expression during the last five years. She was also known internationally for her artwork. She had a warm and sparkling personality and those who knew her will remember her lively discussions, her ready laugh, her spontaneous wit and prolific creative ideas. She was a friend to many and will be sorely missed.

While at Adelaide, Hilary served a period as an Assistant Editor for The ANZIAM Journal and designed its present cover. A derivative of this subsequently became the cover for the Gazette of the Australian Mathematical Society. Her rich artistic creativity was very manifest in the range of very different alternative cover designs that were considered before the final choice for The ANZIAM Journal cover was made. The choice was difficult and at one point we were very close to selecting an intricate Aztéc design in gold. The Journal office currently enjoys the large framed original from which the present cover was extracted as a portion. Hilary's artworks have featured in a number of sole-artist exhibitions in major cities in the Northern Hemisphere.

Hilary acted as a role model for women in the mathematical sciences and successfully juggled the demanding roles of mother, partner, researcher and teacher. In this she followed her mother, a geophysicist, whom she lost when she was only eight. She also managed to find some time for art, though always less than she would have liked. As Sue Wilson notes in a moving obituary in the latest issue of the Gazette of The Australian Mathematical Society, Hilary was a natural teacher and had a wonderful ability to successfully nurture students, to whom she devoted much of her time.

Hilary is survived by her two dearly loved daughters, Lila and Natalie Marvell, to whom we extend our deepest condolences for their loss.

Emma Hunt and Charles Pearce 